\title{
Orçamento orientado a resultados: instrumento de fortalecimento democrático na América Latina?
}

\author{
Martin Francisco de Almeida Fortis
}

\section{Introdução}

A proposta básica do presente artigo é problematizar as possíveis contribuições do orçamento orientado a resultados (OOR) para o processo de consolidação democrática na América Latina. Boas práticas e os estudos de caso sobre OOR costumam ser divulgados em fóruns de especialistas, que reúnem técnicos de governo, consultores de organismos internacionais e pesquisadores da área de administração pública. A produção teórica sobre democracia, entretanto, é conduzida, geralmente, por cientistas políticos e acadêmicos de ciências sociais.

As ideias aqui esboçadas sugerem que a aproximação entre os universos da administração pública e da análise política pode ser benéfica, enriquecendo a qualidade das reflexões e proposições. Se a arena do orçamento é a política, conforme já assinalava o mestre Wildavsky, é desejável ampliar o sentido contemporâneo que o termo vem assumindo. Muito mais do que instrumento técnico ou ferramenta de alocação, o orçamento é espaço decisório no qual o 
poder é distribuído entre atores sociais dotados de valores, preferências e projetos específicos.

O artigo está dividido em quatro partes. A seção inicial apresenta os resultados de alguns estudos sobre percepção democrática na América Latina, mostrando que o amadurecimento do sistema político está diretamente associado aos níveis de confiança da sociedade em suas instituições. Em seguida, discute-se a interessante sugestão de Peter Evans, baseada na sinergia entre Estado e sociedade como estratégia para fomentar patamares mais elevados de confiança. Na seção posterior, são analisadas as principais restrições, desafios, mudanças associadas ao OOR, argumentando-se que, não obstante sua complexidade, a abordagem moderna de orçamentação por resultados pode contribuir para fortalecer as instituições governamentais e produzir avanços democráticos. A seção final propõe que a amplitude das transformações exigidas pelo OOR implica reconceitualizar o orçamento público, conferindo-lhe significado mais abrangente e profundo.

\section{Quadro de desconfiança política na América Latina}

Desde a publicação do pioneiro estudo "Civic Culture: political attitudes and democracy in five nations" por Gabriel Almond e Sidney Verba em 1963, a confiança política consagrou-se na literatura de ciência política como variável decisiva para a compreensão de fenômenos como legitimidade, governabilidade e consolidação do regime democrático. Nos Estados Unidos, por exemplo, a guerra do Vietnã e o caso Watergate já haviam demonstrado como crises de confiança podem afetar (negativamente) a credibilidade dos governos.
A desconfiança possui poder corrosivo sobre as instituições sociais, gerando "suspeição, descrédito e desesperança, comprometendo a aquiescência, a obediência e a submissão dos cidadãos à lei e às estruturas que regulam a vida social". Em se tratando das sociedades contemporâneas, complexas e diferenciadas, a confiança funciona como mecanismo de proteção dos indivíduos contra as incertezas da vida moderna. (MoIsÉs, 2005, p. 41)

Thimothy Power e Giselle Jamison, no artigo "Desconfiança Política na América Latina", discutem os baixos níveis de confiança no sistema político latinoamericano no atual período democrático. Esses autores defendem que "a desconfiança nos políticos é apenas um aspecto de uma síndrome de 'desconfiança generalizada' na América Latina, que inclui pouca confiança interpessoal, desconfiança das instituições, baixa confiança no desempenho do regime e até ceticismo em relação a muitas instituições não governamentais". Segundo eles, o baixo nível de confiança dos latinoamericanos atinge quase todos os tipos de instituições sociais, políticas e econômicas.

Para fundamentar suas análises, Power e Jamison (2005) apresentam dados empíricos sobre níveis de confiança institucionais e interpessoais. Para a série histórica 1996-2003, os resultados apontados pelo Instituto Latinobarômetro para a confiança da população latino-americana em algumas de suas instituições foram: igreja $(70 \%$ $75 \%)$, televisão $(40 \%-50 \%)$, forças armadas $(30 \%-40 \%)$, presidente $\mathrm{da}$ nação (30\%). A Tabela 1 apresenta os índices de confiança nos partidos políticos e no Parlamento.

Não apenas os níveis de confiança institucional são extraordinariamente baixos. As pesquisas do World Values Surveys, para o período 1990-1993, 
mostram que os patamares de confiança interpessoal para a América Latina estão muito aquém dos observados nos países desenvolvidos. O Brasil, por exemplo, ocupa a pior posição com modestíssimos 7\% de confiança. A Tabela 2 sumariza os resultados.

Esses dados evidenciam que as democracias latino-americanas estão distantes de cumprir o critério de consolidação democrática proposto por Larry Diamond em "Developing Democracy: toward consolidation", segundo o qual o apoio para a democracia deve estar próximo de $75 \%$ e a rejeição deve ser inferior a $15 \%$. Nesse caso, como reverter esse cenário? Que instrumentos ou estratégias podem ser mobilizados para elevar os padrões de confiança nas sociedades latino-americanas? No presente artigo, discute-se a capacidade de a reforma orçamentária, conhecida como OOR, enfrentar questões políticas complexas como legitimidade, governabilidade, transparência e cidadania. Antes de discorrer sobre as inovações propugnadas pelo OOR, a seção seguinte aborda a formulação de Peter Evans sobre sinergia.

\section{O papel das instituições:} proposta de sinergia entre Estado e sociedade

O exercício de encontrar explicações para o problema da confiança na América Latina aponta a necessidade de distinguir entre confiança na democracia e confiança no desempenho do governante (MoIsés, 2005). Os cidadãos apreciam as qualidades do sistema político, avaliando questões

Tabela 1: Confiança nos partidos e no Parlamento, América Latina, 1997-2003.

\begin{tabular}{lcc}
\hline Ano da pesquisa & Confiança nos partidos (\%) & Confiança no Congresso (\%) \\
\hline 1997 & 28 & 36 \\
1998 & 21 & 27 \\
$1999-2000$ & 20 & 28 \\
2001 & 19 & 24 \\
2002 & 14 & 23 \\
2003 & 11 & 17 \\
\hline
\end{tabular}

Fonte: Latinobarômetro, reproduzido de Power e Jamison (2005).

Tabela 2: "Pode-se confiar na maioria das pessoas?"

\begin{tabular}{lc}
\hline País / Região & Índice de confiança interpessoal (\%) \\
\hline Escandinávia & $58-66$ \\
Canadá e Estados Unidos & $50-52$ \\
Itália e Espanha & $34-37$ \\
México & 33 \\
Chile e Argentina & 23 \\
Brasil & 7 \\
\hline
\end{tabular}

Fonte: World Values Surveys, citado por Power e Jamison (2005) 
como legitimidade da democracia, participação eleitoral, representatividade do Parlamento, satisfação com os partidos políticos existentes. A qualidade da cidadania está relacionada aos atributos essenciais do regime democrático: sufrágio universal; direito de eleger e ser eleito; eleições livres e regulares, desprovidas de coerção; proteção ao direito de livre expressão, inclusive críticas ao governo, regime, sociedade ou ideologia dominante; existência de fontes alternativas de informação; direito de constituir organizações autônomas, inclusive partidos de oposição; responsividade dos governos aos votos dos eleitores e aos resultados das eleições (DAHL, 1989).

A outra dimensão da confiança refere-se à função operativa, executora do governo. Nesse caso, a população examina a capacidade governamental de atender a suas demandas mediante a implementação de políticas públicas efetivas, avaliando a performance dos governantes. A análise do cidadão tende a ser direcionada para assuntos de interesse local, como qualidade do ensino nas escolas, disponibilidade de vagas nos hospitais públicos, qualidade do transporte coletivo, eficiência dos policiais em prevenir violência urbana etc.

Se no nível municipal, os cidadãos se preocupam com a adequação dos serviços prestados, no nível nacional os eleitores estão atentos ao desempenho das variáveis macroeconômicas, como salários, taxas de juros, de inflação e de desemprego. Instituições que funcionam satisfatoriamente ganham a confiança dos cidadãos: órgãos e entidades governamentais que "funcionam de acordo com o fim para o qual existem ou com a eficiência necessária para o cumprimento de sua missão" melhoram os padrões de confiança vigentes na sociedade (MoIsÉs, 2005).
Será que essas duas dimensões (garantia dos direitos democráticos e efetividade das políticas públicas) possuem comportamento associado? Será que desempenhos econômicos sofríveis abalam o valor percebido da democracia? O "paradoxo democrático" consiste no fato de que a redução da confiança nas instituições não tem sido acompanhada por declínio semelhante da confiança na democracia (DAHL, 2000).

A cultura política parece ser variável essencial na explicação desse paradoxo, fornecendo o lastro de preservação dos padrões democráticos em contextos de performances governamentais pífias:

Apesar de a cultura política democrática poder ser erodida se um número grande de cidadãos persistentemente avaliar o governo como altamente ineficiente em lidar com problemas que realmente importam para eles, uma forte cultura democrática auxiliará a preservar até um governo pouco efetivo por um período de tempo considerável. $\mathrm{Na}$ Itália, por exemplo, apoio para a democracia é razoavelmente alto, apesar da performance desastrosa no governo nacional desde 1945 (DAHL, 1996).

A cultura política pressupõe confiança do cidadão no regime democrático. Peter Evans (1996) salienta os benefícios da interação sinérgica entre Estado e sociedade, mostrando que o estreitamento entre "cidadãos mobilizados com agências públicas pode melhorar a eficácia do governo. A combinação de fortes instituições públicas com comunidades organizadas é uma ferramenta poderosa para o desenvolvimento". Evans explica que três variáveis são decisivas para determinar o grau de sinergia de uma sociedade: estoque 
de capital social, níveis de desigualdade e configuração dos arranjos institucionais. Dados empíricos comprovam que sociedades com laços interpessoais frágeis, altamente desiguais e excessivamente hierarquizadas enfrentam sérias restrições na construção de sinergia.

O caso brasileiro é emblemático: os persistentes déficits sociais apresentam-se como entraves à consolidação democrática da nação, tornando a cidadania privilégio de parcelas restritas da população. Os padrões históricos de exclusão e desigualdade confinam o acesso aos serviços públicos a minorias aquinhoadas, constituindo modelo de "cidadania regulada". Santos (1993) identifica uma dicotomia institucional que opõe esforços de construção democrática a práticas predatórias de hobbesianismo social, provocando instabilidade e descrédito institucional.

Nesse contexto de fortes restrições institucionais, como parece ser o caso da maioria dos países latino-americanos, como desenhar e implementar soluções sinérgicas? Evans sugere estimular avanços nas instituições públicas orientando-as para descentralização e abertura das hierarquias burocráticas, tornando-as permeáveis às demandas dos níveis inferiores da sociedade.

Essa estratégia implica ruptura com duas importantes características de parte expressiva das instituições públicas: formalismo (CORE, 2005) e insularidade (SCHICK, 2005). O formalismo significa que as tentativas de mudança são refreadas e, ao invés de promover modernização dos aparatos burocráticos, resultam na permanência de estruturas e procedimentos consolidados pela tradição. Por sua vez, a insularidade, comportamento típico das instituições responsáveis pelas finanças públicas, implica processos decisórios altamente hierarquizados, com baixa permeabilidade à participação ou envolvimento de atores estranhos ao núcleo de poder das instituições.

A ênfase na interação com a sociedade em processos institucionais de definições de políticas públicas é elemento importante para fortalecer a cultura política. Conforme se afirma adiante, a implantação do OOR pode ser uma ferramenta eficaz para incentivar o rompimento com padrões históricos da administração pública,

"As evidências

indicam que

ferramentas modernas,

técnicas avançadas,

metodologias

sofisticadas não

surtirão os benefícios

desejados se as

instituições não

estiverem

adequadamente

preparadas para

aperfeiçoar seus

padrões

organizacionais."

eliminar persistentes patologias burocráticas e tornar as instituições mais transparentes e receptivas ao diálogo com a sociedade.

Evans (1996) alerta, porém, para os riscos inerentes à flexibilização das estruturas burocráticas. Maior exposição à captura do poder público por interesses privados (como os casos clássicos de clientelismo, comportamentos de rentseeking e práticas de corrupção) é inevitável 
quando a descentralização e a abertura das instituições são estimuladas. Por esses motivos, e em se tratando de países em desenvolvimento, a avaliação de Peter Evans sobre a aproximação cidadãogoverno é pessimista:

Se sociedades igualitárias com burocracias públicas robustas fornecem o solo mais fértil para relações estadosociedade sinérgicas, a maioria dos países do terceiro mundo oferece perspectivas áridas. Uma vez que estruturas sociais altamente desiguais são comandadas por frágeis aparatos governamentais, não surpreende que a maioria dos estudos das relações Estadosociedade sejam pródigos em exemplos negativos (Evans, 1996, p. 201).

Se, como foi exposto, existem sérias ressalvas à introdução de práticas sinérgicas em virtude de restrições nas dotações, especialmente escasso capital social, padrões persistentes de desigualdade e burocracias ineficientes, como superar esses fatores de limitação? Examina-se, na seção seguinte, até que ponto o OOR pode promover modernização institucional e administrativa dos governos e quais são seus potenciais benefícios para o fortalecimento democrático.

\section{Orçamento orientado a resultados} (OOR): resgate da efetividade das políticas governamentais como instrumento de fortalecimento da democracia

A té aqui se procurou demonstrar que: a) a confiança (interpessoal e institucional) é ingrediente crucial da consolidação democrática; b) os níveis de confiança na América Latina são muito baixos; c) a reversão desses padrões modestos de confiança está positivamente associada com a revitalização ou construção de instituições governamentais eficazes; d) a existência de cultura política baseada em valores, normas e tradições democráticas é relevante para sobrevivência do sistema político em contextos econômicos adversos; e) a sinergia (proposta por Evans) é instrumento útil para conectar a efetividade do desempenho governamental com o fortalecimento do regime democrático.

Nesta seção, discute-se a capacidade do OOR de contribuir para reverter os baixos níveis de confiança existentes na América Latina mediante o impulso para construção de relações sinérgicas entre sociedade e Estado. Essa conexão não é imediata, especialmente por conta do viés notadamente instrumental que o orçamento público tem recebido atualmente. Em particular, a utilização do orçamento como instrumento de equilíbrio fiscal tem favorecido uma interpretação minimalista, negligenciando as dimensões políticas intrínsecas ao processo de orçamentação.

Antes de iniciar o debate sobre o potencial sinérgico do orçamento, cumpre resgatar o conceito de OOR. A ideia básica é a superação da administração pública tradicional baseada em insumos e controles, mediante a introdução de paradigma voltado para o desempenho eficiente das políticas públicas (Diamond, 2005; Tom Liou, 2007).

Em breve recuperação histórica, verifica-se que o OOR não é exatamente novidade, constituindo-se em uma série de reformas orçamentárias iniciada na década de 1950:

Governos em alguns países desenvolvidos declararam guerra, há 50 anos, contra o incrementalismo, ao 
introduzir um conjunto de reformas voltadas para tornar o processo mais estratégico. Desde o orçamentodesempenho nos anos 50, orçamentação por programa e sistemas de planejamento-programação-orçamento (PPBS) nos 60, orçamento base-zero nos 70 e orçamento por resultados nos anos 80 e 90, governos têm procurado tornar o processo de algum modo menos incremental e mais responsivo a mudanças nas prioridades nacionais. Cada falha demarca o cenário para a próxima reforma. Atualmente, os anti-incrementalistas concentram sua força no orçamento baseado em desempenho e no marco de gastos de médio prazo (MTEF) (SCHICK, 2008, p. 8).

O professor emérito da Universidade de Maryland Allen Schick revela a complexidade da implementação dessas reformas orçamentárias, interrogando em artigo recente: "O que é tão difícil sobre OOR, que, 60 anos após o conceito ter sido introduzido, ainda está tentando ganhar força como um dos métodos aceitos para alocação de recursos no governo?”.

O estudo das razões do insucesso das diversas reformas orçamentárias propugnadas desde a década de 1950 fornece pistas úteis para construção de futuro promissor. Evidentemente, as causas são múltiplas e certamente dependem do contexto em que sejam aplicadas. Um traço comum, entretanto, parece estar relacionado à dificuldade em desenvolver os requisitos gerenciais necessários à implantação de novos modelos orçamentários. As evidências indicam que ferramentas modernas, técnicas avançadas, metodologias sofisticadas não surtirão os benefícios desejados se as instituições não estiverem adequadamente preparadas para aperfeiçoar seus padrões organizacionais. Um primeiro corolário extraído dos ensinamentos das reformas orçamentárias recentes é que o OOR pressupõe rompimento com "padrões essenciais da cultura organizacional e modos tradicionais de administração, nos quais predomina o cumprimento formal dos meios sobre a execução dos fins".

Em se tratando de mudanças organizacionais e rupturas de paradigmas, é interessante observar o hiato que separa o setor público do privado. No sistema de livre concorrência, as empresas ineficientes tendem a ser eliminadas do mercado. A busca pelo lucro, a vigilância constante dos acionistas, a velocidade dos avanços tecnológicos, os padrões crescentes de competitividade geram incentivos permanentes para inovação empresarial. No mundo corporativo, filosofias e escolas de administração têm sistematicamente procurado oferecer soluções voltadas para elevar níveis de produtividade, maximizar desempenho organizacional, satisfazer o cliente, otimizar a qualidade do produto, reduzir desperdícios e mensurar custos.

Para reduzir esse hiato, iniciou-se na década de 1980 um ciclo de reformas da administração pública, conhecido como Nova Gestão Pública (NGP), que advogou a aplicação de soluções gerenciais adotadas nas empresas privadas às organizações governamentais, tendo por experiências mais notáveis países como Inglaterra e Nova Zelândia. Entre outros, os pilares da NGP foram: a) foco no cliente ou cidadão; b) orientação por resultados; c) privatização, descentralização e delegação na produção de bens e serviços; d) introdução de arranjos contratuais como sistemas de incentivo à competição; e) fomento à implantação de agências executivas; f) planejamento estratégico para implementação de políticas 
públicas efetivas na entrega de serviços públicos; g) monitoramento e avaliação de desempenho; h) flexibilização da atuação dos gerentes nas organizações, com doses crescentes de autonomia e responsabilidade.

$\mathrm{Na}$ avaliação de Nick Manning, a NGP deixou marcas, mas não foi capaz de transformar o paradigma burocrático tradicional. Ele afirma ainda que a internalização dos princípios da NGP em países em desenvolvimento foi inferior às expectativas iniciais da reforma. Evidências apontam para a necessidade de preencher certas precondições, ou alcançar determinado patamar gerencial, antes de introduzir os níveis de flexibilidade e autonomia propugnados pela reforma (SCHICK, 1998).

Além da ideia de maturidade institucional, que sugere a existência de etapas sucessivas na implantação de reformas orçamentárias, é válido notar que as trajetórias dependem do contexto no qual estão inseridas. A gestão pública não ocorre no vácuo, sendo descabida a ideia de uma receita universal, panaceia aplicável indistintamente a qualquer nação, pois “a orçamentação está incrustada em normas, tradições, culturas, práticas e relacionamentos de gestão pública. Governos orçam da forma como gerenciam, razão pela qual é tipicamente necessário modernizar práticas gerenciais para conseguir reformar o processo orçamentário" (Schick, 2008, p. 17-18).

Países dotados de práticas de gestão mais modernas estão mais aptos a implementar o OOR, desfrutando de vantagem comparativa: "Países que mais avançaram em orçamentação baseada em resultados estavam entre os mais bem geridos no mundo. Eles possuem reputação de terem baixa corrupção, administração pública eficiente, arranjos de prestação de contas efetivos, canais políticos e administrativos para os cidadãos expressarem preferências e insatisfações, e procedimentos para monitorar a qualidade dos serviços públicos” (SCHICK, 2008, p. 18).

Em que pese a necessidade de os países customizarem seus desenhos e estratégias, parece existir um inimigo comum que impede o sucesso das reformas orçamentárias: a capacidade de executar mudanças estruturais nos aparatos burocráticos. A mudança pretendida pelo OOR não é apenas organizacional, nem de modificação de procedimentos. Trata-se da revisão de padrões culturais, institucionais, comportamentais. Em verdade, essa mudança ao OOR atinge a própria cultura política do país que, em última instância, estabelecerá os padrões pelos quais os políticos enxergarão os eleitores, os governantes perceberão os cidadãos, os servidores públicos encararão seus "clientes". A discussão sobre sinergia de Evans (1996) mostra que o distanciamento entre sociedade e Estado dilapida o capital social da nação, abalando os níveis de confiança e a vitalidade da democracia.

Em relação às mudanças diretamente incidentes sobre a administração pública, merecem destaque algumas dimensões: a) criação de valores, normas e padrões que sejam compatíveis com a cultura de resultados; b) instrumentalização de novo modelo administrativo que promova modificações nos critérios tradicionais de utilização de recursos; c) alteração no modo de funcionamento das instituições, substituindo o incrementalismo pelo gerencialismo; d) aperfeiçoamento de regras, procedimentos, sistemas e processos orçamentários; e) fixação de incentivos ao desempenho da burocracia.

Schick (1998) sustenta a existência de uma sequência lógica para construção da capacidade gerencial no setor público, 
sublinhando alguns passos cruciais como: a) produção de avanços similares no setor privado (não é racional supor que o setor público lidere o processo de inovação); b) estabelecimento de controles externos operativos e confiáveis; c) consolidação dos sistemas, estruturas e processos básicos da gestão pública, antes de se pretender introduzir refinamentos excessivamente sofisticados; d) desenvolvimento de controles internos voltados para verificação de conformidade com as regras e a preservação dos ativos públicos.

Marcos Makón, no elucidativo artigo "A gestão por resultados é sinônimo de orçamento por resultados?", acrescenta outros ingredientes necessários à formação da capacidade gerencial. Ele tem razão em atrelar o sucesso na implantação do OOR ao correto desenho de sistema de incentivos, que beneficie as diversas dimensões da realidade das organizações públicas: institucional, organizacional, orçamentária, recursos humanos, contratos e compras. Entre os principais itens da agenda de gestão por resultados, destacam-se:

- Foco nos resultados;

- Políticas públicas formuladas a partir de processo de planejamento governamental;

- Caráter descentralizado da tomada de decisões;

- Flexibilização de recursos com cobrança de responsabilidade dos gestores;

- Utilização de planejamento estratégico nas organizações públicas e otimização dos processos administrativos;

- Mudanças metodológicas no processo de formulação do orçamento público;

- Sistemas de informação que forneçam subsídios para a tomada de decisão e mensurem os recursos consumidos na obtenção dos resultados (sistemas de apuração de custos);

- Sistemas de monitoramento da gestão, prestação de contas e avaliação;

- Desenvolvimento de indicadores que permitam medir o impacto da ação governamental e identificar os desvios para introdução de medidas corretivas.

Trata-se evidentemente de mudanças complexas, que exigem comprometimento e liderança governamental. Essa liderança demanda participação de outros atores e extrapola a esfera orçamentária, invadindo a seara da cultura política: "Extirpar patologias alastradas no comportamento e desempenho do servidores públicos foge à alçada do processo orçamentário e alcança os valores sociais e políticos fundamentais" (SCHICK, 2005, p. 18). Dessa forma, o orçamento é agente decisivo do processo de modernização governamental, mas possivelmente insuficiente para assegurar o alcance do paradigma gerencial.

É importante considerar que a própria noção de orçamento precisa ser problematizada. O orçamento é simultaneamente instrumento de formulação de políticas públicas e mecanismo de promoção da democracia, pois é por intermédio dos bens e serviços recebidos que o cidadão avalia seu governo. O papel do orçamento não se restringe à mera financeirização do planejamento, cabendo-lhe mais do que simplesmente atribuir recursos a programações governamentais.

Nessa visão ampliada do orçamento, torna-se consistente a proposta de OOR, que visa pressionar por maior eficiência não somente dos governantes, mas também da burocracia. Schick acredita que o êxito do OOR "depende mais das competências e atitudes dos servidores públicos do que de sistemas e procedimentos". Makon reforça a importância do papel da burocracia no 
processo de mudança: “o êxito das políticas de modernização está vinculado ao grau de motivação e predisposição para a mudança que demonstrem os servidores públicos".

Entre as mudanças vislumbradas no OOR, destaca-se a revisão do papel dos órgãos centrais de orçamento, que são tradicionalmente caracterizados por insularidade ou alheamento. Insularidade significa atuação isolada dos demais órgãos de governo, criando cinturão protetor contra participação (ou penetração) de atores não "autorizados" a se envolver nas definições de alocação de recursos orçamentários; por seu turno, alheamento implica preocupação em alocar recursos de forma desvinculada dos seus efeitos sobre a sociedade.

De certa forma, a insensibilidade das instituições orçamentárias ao envolvimento popular pode ser explicada por sua natureza tecnocrática. Allen Schick nos lembra que essa condição é contingente, já que, no momento histórico de seu surgimento, o orçamento, ao cercear o poder discricionário dos reis, foi concebido como mecanismo de democratização. Contemporaneamente, porém, o forte conteúdo técnico, o entendimento confinado a especialistas e a linguagem codificada do orçamento público têm inibido o exercício democrático. $\mathrm{O}$ futuro pode testemunhar tendências de pressão da sociedade por maior transparência e envolvimento:

Em seus estágios iniciais séculos atrás, a orçamentação surgiu como um meio de democratizar o governo mediante a limitação dos montantes que ele gastava e tornando os líderes responsáveis pelas suas ações. Em tempos recentes, a orçamentação tem tendido a retardar a expressão democrática porque ela é um processo fechado, tecnocrático. Essa generalização aplica-se às democracias de todo o mundo; não se refere exclusivamente aos países da América Latina. Esforços para tornar a gestão das finanças públicas mais transparente objetivam redemocratizar o processo. Não deve se surpreender se essa tendência ganhar força nas décadas vindouras e comandar a atenção dos políticos e orçamentocratas nos países desenvolvidos e em desenvolvimento (SCHICK, 2005, p.19).

A temática da transparência não se resume a dar visibilidade à gestão das políticas públicas. Além dessa dimensão de acessibilidade, a abertura das contas públicas visa, sobretudo, oferecer ferramentas aos cidadãos para múltiplos fins: a) compreender a intrincada linguagem orçamentária, fornecendo subsídios para que a população exerça suas competências cívicas e, portanto, aprimore suas práticas de cidadania; b) fiscalizar e monitorar a execução das atividades governamentais, atuando como fator inibidor de corrupção e outros vícios, como clientelismo e patrimonialismo; c) avaliar o desempenho dos gestores, incentivando a eficiência operacional da administração pública e a efetividade das políticas públicas; d) oferecer oportunidades para participar no processo de definição das políticas setoriais a serem implementadas (FORTIS, 2008).

Além das posturas isolacionistas e refratárias ao diálogo, outras tradicionais competências dos órgãos centrais de orçamentação precisam ser repensadas. Que tipos de questões passariam a ser incorporadas na agenda orçamentária? Quais novas competências seriam agregadas pelos órgãos centrais de orçamento? 
Seria necessário ver a orçamentação de forma mais ampla, não apenas como uma forma de alocar recursos financeiros para programas de governo e agências, mas também como um instrumento decisivo para promover desenvolvimento econômico e social, estabilizar condições financeiras e reduzir exposição a vários riscos e choques, aperfeiçoar a governança pública e a capacidade gerencial geral, construindo politicamente legitimidade e tornando os governos nacionais e seus orçamentos mais responsivos ao desejo democrático (SCHick, 2005, p. 2).

Outra missão importante do OOR é combater a informalidade que reina na arena orçamentária que, ao buscar superar os entraves burocráticos e controles excessivos, abre espaço para corrupção e ineficiência. Quando a informalidade predomina, o governo possui dois orçamentos: existe um documento formalmente aprovado pelo Parlamento, mas que é pouco realista e raramente implementado e há, paralelamente, um orçamento informal, constituído por desembolsos financeiros, que corresponde aos gastos efetivamente realizados pelo governo. A orientação por resultados pode contribuir favoravelmente para que o orçamento seja um contrato implícito e não mera declaração de intenções (SCHICK, 1998).

A implantação do OOR implica, ao menos para os países em fase de desenvolvimento, uma perspectiva ampla, que inclua assuntos como cultura política, confiança, governança, democracia, estabilidade institucional, além dos temas mais recorrentes de efetividade do desempenho e melhoria gerencial. Pode-se argumentar que o padrão sinérgico de governança democrática, no qual cidadãos e governo interagem de forma cooperativa, sistemática e transparente, ainda é uma aspiração distante na maioria dos países latinoamericanos.

Makón (2008, p. 13) sustenta a existência de um "vazio" entre governo e sociedade civil, resultante da ausência de instituições intermediárias que pudessem articular as demandas dos diferentes grupos sociais e estabelecer mecanismos

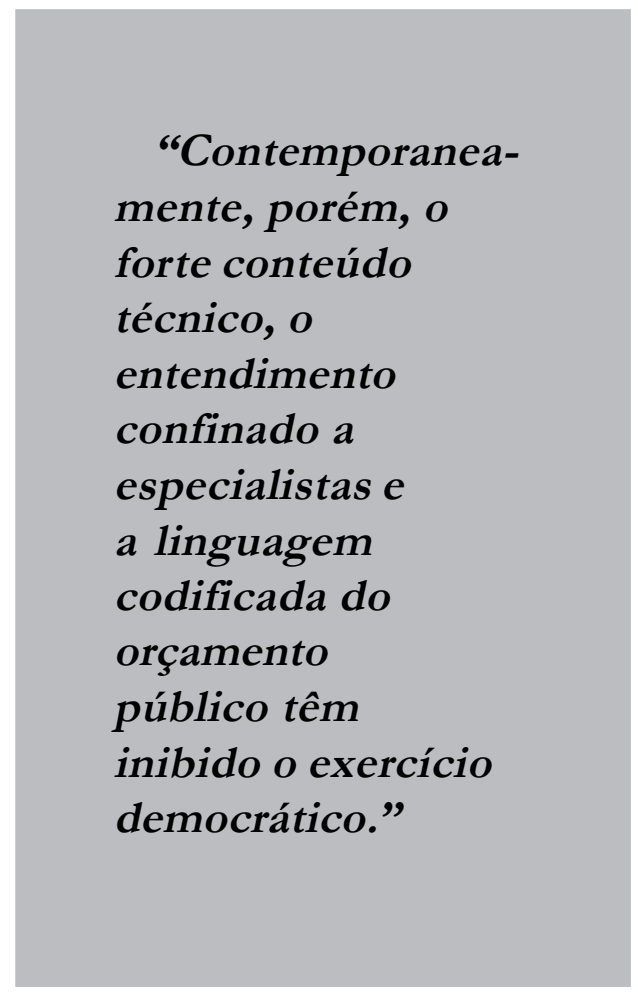

de comunicação mais efetivos entre a ação governamental e as aspirações populares. A inexistência de padrões institucionalizados de interação da sociedade com o governo, especialmente na esfera orçamentária, reflete-se no insulamento das agências de orçamento, bem como parece estar relacionada com o caráter tecnocrático do orçamento. Sem a introdução de mudanças estruturais, particularmente 
as que caracterizam o OOR, a sinergia advogada por Evans não poderá fluir entre as veias do Estado.

\section{Conclusões}

A tese central deste artigo é que o OOR consiste em ferramenta poderosa para despertar relações de sinergia, mediante arranjos institucionais que aproximem Estado e sociedade. Instituições governamentais são fatores decisivos para o desempenho das políticas públicas e também para construção da legitimidade democrática, pois ao transformar programas de governo em bens e serviços que atendam as demandas sociais, tendem a elevar o nível de confiança da sociedade e fortalecer a democracia.

O OOR implica concepção mais abrangente do orçamento público, tornando-o um valioso instrumento para promover a sinergia de Evans. A primeira conclusão, portanto, é que as transformações resultantes do OOR extrapolam a esfera da efetividade das políticas públicas e das mudanças organizacionais, contribuindo para fomentar o capital social, ampliar os níveis de confiança, fortalecer as instituições democráticas e legitimar o regime democrático. Jack Diamond sintetiza a ideia: a ênfase no resultado constrói confiança e melhora a credibilidade perante os contribuintes (Diamond, 2005, p. 4).

Nessa acepção ampla de orçamento como mecanismo de governança democrática, novas tendências se destacam: a) rompimento do paradigma tecnocrático tradicional das instituições orçamentárias, baseado no isolamento e no formalismo; b) implantação de cultura de resultados mediante construção de novos valores, normas, práticas; c) introdução de sistemas de incentivo para premiar o desempenho eficiente dos servidores públicos; d) participação ativa, consciente e crítica da sociedade civil na gestão pública, estabelecendo relação cooperativa, sinérgica e transparente; e) adoção de padrões gerenciais modernos, que maximizem os benefícios das políticas públicas e o desempenho operacional da administração pública; f) compromisso do orçamento com objetivos nacionais primordiais, especialmente crescimento econômico com inclusão social.

A sinergia cidadão-governo representa a aproximação dos universos da policy e da politics. Políticas públicas não são apenas recursos para solucionar problemas ou aproveitar oportunidades, mas mecanismos de exercício da democracia. Por um lado, privilegia-se o desenvolvimento socioeconômico e a efetividade da gestão governamental; por outro, aspira-se a reforçar a aceitação popular do sistema político e ampliar a confiança nas instituições democráticas.

Apesar de o orçamento público ser percebido estritamente como instrumento técnico, as propostas do OOR assumem dimensão política. A conexão entre orçamento e política não se resume ao ato solene de aprovação do documento orçamentário pelo Parlamento. Muito mais do que isso, o orçamento é a arena na qual os atores sociais exercem seu poder de influência, autoridade, legitimidade, escolha e decisão. $\mathrm{O}$ orçamento é por excelência mecanismo de agregação de preferências que, procurando solucionar problemas de ação coletiva, deve almejar traduzir os desejos e aspirações das sociedades.

O orçamento representa o consenso possível resultante de desejos virtualmente ilimitados dos múltiplos atores sociais. $\mathrm{O}$ mestre Wildavsky dizia que os orçamentos são elos entre recursos financeiros e 
comportamento humano, a fim de alcançar objetivos políticos.

Conforme se argumentou ao longo do artigo, as reformas propugnadas pelo OOR são estruturais e, por isso, de difícil implementação. Porém, seus benefícios são nobres e desejáveis, especialmente para os países e povos da América Latina.
A agenda de mudanças do OOR configura-se como elemento crucial no combate a inimigos históricos persistentes, contribuindo para consolidar sociedades mais democráticas, justas, legítimas e solidárias.

(Artigo recebido em fevereiro de 2009. Versão final em junho de 2009)

\section{Referências bibliográficas}

Core, Fabiano Garcia. Reforma gerencial dos processos de planejamento e orçamento. Texto para discussão - ENAP. Brasília: outubro, 2001.

- Reformas orçamentárias no Brasil: uma trajetória de tradição e formalismo na alocação dos recursos públicos. Revista $A B O P$, v. 23, no 47, 2005.

DAHL, Robert. Democracy and its critics. New Haven: Yale University Press, 1989.

. The future of democratic theory. Working Paper n. 90, Center for Advanced Study in the Social Sciences of Juan March Institute,1996.

A democratic paradox? Political Science Quarterly. Vol. 115, n 1, 35-40.

Spring, 2000.

Diamond, Jack. Establishing a Performance Management Framework for Government, Working Paper 05/50, IMF, 2005.

Evans, Peter. Government Action, Social Capital and Development: Reviewing the Evidence on Synergy. World Development, 24:6, p. 1119-1132, 1996.

ForTIS, Martin. Transparência e controle social no governo federal brasileiro: análise dos principais avanços e desafios no período pós-LRF. Revista Internacional de Presupuesto Público, $\mathrm{n}^{\circ}$ 68, ano 36, novembro-dezembro de 2008.

Makón, Marcos Pedro. La gestión por resultados es sinónimo de presupuesto por resultados? Revista Internacional de Presupuesto Público, n 66, ano 36, março-abril de 2008.

Moisés, José Álvaro. A desconfiança nas instituições democráticas. Opinião Pública, Campinas, v. 11, no 1, 2005.

Power, Timothy J.; Jamison, Giselle D. Desconfiança Política na América Latina. Opinião Pública, Campinas, v. 11, no 1, 2005.

Santos, Wanderley Guilherme dos. Razões da Desordem. Rio de Janeiro: Hucitec, 1993.

ScHICK, Allen. Getting Performance Budgeting to Perform. Performance Budgeting International Conference, Mexico, Junho de 2008. Disponível em: http:/ / siteresources.worldbank.org/ MEXICOINSPANISHEXT/Resources/ConceptPaperAllenSchickFinal.pdf . An Agenda for Budgeting. A Concept Paper for Establishing a Budget

Network in the LAC Region. 2005. 
. Why most developing countries should not try New Zealand's reforms. World Bank Research Observer 13(1), p. 123-131, 1998.

Wildavsky, Aaron. The new politics of the budgetary process. Second Edition. New York, NY: Harper Collins Publishers, 1992.

Tom Liou, Kuotsai. Applying good governance concept to promote local economic development: contribution and challenge. International Journal of Economic Development, Jan-April, 2007. 


\section{Resumo - Resumen - Abstract}

\section{Orçamento orientado a resultados: instrumento de fortalecimento democrático na} América Latina?

Martin Francisco de Almeida Fortis

O presente artigo discute a relação entre orçamento e democracia, argumentando que as transformações propugnadas pela orçamentação por resultados possuem não somente benefícios gerenciais para a administracao pública, mas também efeitos positivos sobre o sistema político e suas instituiçoes. Dados empíricos demonstram que os padrões de confiança institucional na América Latina são baixos, apesar de a confiança no regime democrático ser significativamente maior. A implantação do modelo de orçamento orientado a resultados (OOR) representa ruptura com o paradigma tradicional de gestão pública, propondo a substituição do foco nos insumos, controles, regulamentos e conformidade pela ênfase na ação estratégica, efetividade do gasto público, flexibilidade gerencial, accountability e participação da sociedade. A formulação de políticas públicas orientadas para as necessidades dos cidadãos fomenta o capital social da comunidade, alavancando relações sinérgicas entre governo e sociedade. Esse estreitamento fortalece as instituições democráticas na medida em que favorece o monitoramento do desempenho do governante pela sua comunidade e, especialmente, contribui para aprimorar os mecanismos de representação política.

Palavras-chave: orçamento, democracia, confiança institucional.

Presupuesto orientado hacia resultados: ¿instrumento de fortalecimiento democrático en América Latina?

Martin Francisco de Almeida Fortis

El presente artículo discute la relación entre presupuesto y democracia, defendiendo que las transformaciones sugeridas en la presupuestación por resultados poseen beneficios gerenciales no solamente para la administración pública, pero también efectos positivos sobre el sistema político y sus instituciones. Datos empíricos demuestran que los niveles de confianza institucional en la America Latina son bajos, pero que la confianza en la democracia es significativamente mayor. La implementación del modelo de presupuestación orientada a resultados (POR) representa una ruptura con el paradigma tradicional de gestión pública, proponiendo sustituir el foco en los insumos, controles, reglamientos y conformidades por la acción estratégica, efectividad del dispendio público, flexibilidad gerencial, rendición de cuentas y participación de la sociedad. La formulación de políticas públicas dirigidas para las necesidades de los ciudadanos promove el capital social de la comunidad, incentivando relaciones sinérgicas entre gobierno y sociedad. Esa aproximación fortalece las instituciones democráticas, pues favorece el monitoreo del desempeño del gobernante por su comunidad y, particularmente, contribuye para perfeccionar la representación política.

Palabras clave: presupuesto, democracia, confianza institucional.

\section{Results-Oriented Budget: instruments to strengthen democracy in Latin America? Martin Francisco de Almeida Fortis}

The present article discusses how budget and democracy are linked, stating that the changes advocated by the performance budgeting not only benefit managerially the public administration, but also has positive effects over the political system and its institutions. Empirical evidence shows that institutional confidence levels in Latin America are poor, but trust in democracy is significantly higher. The implementation of results-oriented-budget (ROB) represents a breach to traditional public management paradigm, replacing the focus on inputs, controls, regulations and compliance 
for strategic action, effectiveness of public expenditure, accountability and society participation. The formulation of public policies targeting citizen's needs foster the social capital of the community, strengthening synergic relations between government and society. Such a closer relationship vitalizes democratic institutions because it enables communities to monitor their official's performance and thus contributes to enhancing political representation.

Keywords: budget, democracy, institutional confidence.

Martin Francisco de Almeida Fortis

Graduado em Economia pela Universidade de São Paulo e pós-graduando em Ciência Política pela Universidade de Brasília. É servidor da carreira de Planejamento e Orçamento do governo federal, ocupando atualmente o cargo de gerente de projeto da Secretaria de Orçamento Federal.

Contato: martin.fortis@planejamento.gov.br 